\title{
INVESTIGATION RELATIVE TO B. WELCHII INFECTION OF THE INTESTINAL TRACT AS THE ETIOLOGICAL FACTOR IN PERNICIOUS ANEMIA ${ }^{1}$
}

BY ROBERT N. NYE

From the Thorndike Memorial Laboratory, Boston City Hospital, Boston

(Received for publication December 22, 1926)

This work was originally undertaken with the purpose of confirming Herter's (1) and Simonds' (2) observations on the prevalence of $B$. Welchii in the stools of patients with pernicious anemia. In view of the toxin produced by all strains, the marked hemolytic properties of many strains of $B$. Welchii and the presence of anemia associated with $B$. Welchii infection as reported by Klotz and Holman (3) and of hemoglobinuria as noted by Herter (1) and by Schumm (4), chronic infections with $B$. Welchii of some portion of the gastro-intestinal tract with consequent absorption of hemolysins seemed to offer an attractive and quite plausible etiology for the disease, pernicious anemia. The possibility of intestinal absorption as an etiological factor in pernicious anemia was seriously considered a number of years ago by Hunter (5), and more recently the idea has been mentioned by van der Reis (6) and upheld by Seyderhelm (7).

Within the past year several articles have appeared which correlate $B$. W clchii with pernicious anemia. Kahn (8) examined bacteriologically the stools from patients suffering from various diseases in which chronic intestinal infection was a possible etiological factor, and reports as the only consistent finding the presence of considerable numbers of $B$.Welchii spores and the absence of spores of the other common anaerobes in all the stools from cases of pernicious anemia. Moench, Kahn and Torrey (9) write in more detail on the bacteriological examination of 72 stool specimens from 33 cases of pernicious anemia. They found uniformly high $B$. coli counts and $B$. Welchii spore counts

${ }^{1}$ Read in part before the American Society for Clinical Investigation at Atlantic City, N. J., May 3, 1926. 
and were able to recover the latter in pure culture from 26 cases. These organisms were essentially identical with strains isolated from normal stools in their cultural characteristics, hemolysin production and pathogenicity. They conclude that "if these bacilli are of etiologic importance in pernicious anemia it must be on the basis of their excessive numbers and activities, particularly at levels of the intestine where absorption is active and where they are commonly found only in negligible numbers." Cornell (10) has been able to produce anemia, loss of weight, convulsions, diarrhea and eventually death in rabbits by chronic infection with $B$. Welchii. The anemia though usually mild, is sometimes acute and profound. In all cases it is characterized by anisocytosis, and he believes this to be due to the direct action of the toxin on the erythrocytes. He states, "it is not unreasonable to imagine that pernicious amenia might be a chronic infection by B. Welchii." Kahn and Torrey (11) by repeated intravenous injections of suitable amounts of potent $B$. Welchii toxin in two monkeys have produced severe anemias of a type resembling pernicious anemia. Both monkeys within 20 days developed an active immunity which rendered further injections of toxin inocuous in spite of increased dosage. By repeated intramuscular injections of cultures and toxin of B. Welchii, Patterson and Kast (12) were able to produce in rabbits severe to moderate anemias of secondary type accompanied by anisocytosis, polychromatophilia, poikilocytosis, and increase in nucleated red cells.

The work reported in this paper agrees with that of Kahn in confirming the findings of Herter and Simonds. Additional evidence is presented which suggests a somewhat different interpretation of the findings.

\section{EXPERIMENTAL}

B. Welchii spore counts. The characteristic stormy fermentation produced in milk cultures by $B$. Welchii was chosen as the means of determining the number of spores, and the method used was essentially a modification of one devised by Simonds (2).

Method. The specimens were collected in the wards and brought to the laboratory. All watery and enema stools were discarded. Approximately all of the stool was broken up in a glass beaker in $500 \mathrm{cc}$. of freshly prepared 0.9 per 
cent salt solution by means of a glass rod. One hundred cubic centimeters of the emulsion were placed in a bottle, tightly corked and shaken vigorously in a shaking machine for 30 minutes. Another $100 \mathrm{cc}$. were transferred to a tared evaporating dish, dried first on a steam bath and then in a desiccator, and weighed. The shaken emulsion was filtered through 10 thicknesses of sterile gauze to remove gross particles, and approximately $10 \mathrm{cc}$. transferred with a sterile pipette to the bottom of a sterile test tube measuring $250 \times 27 \mathrm{~mm}$. The upper half of the tube was heated very hot in a Bunsen flame to eliminate accidental contamination. The tube was then immersed, at least to half its length, in a water bath at $80^{\circ} \mathrm{C}$. for 20 minutes, thus destroying all vegetative forms of bacteria. One cc. of the heated emulsion was then transferred to a $250 \times 27 \mathrm{~mm}$. tube containing $9 \mathrm{cc}$. of sterile 0.9 per cent salt solution and another $1 \mathrm{cc}$. to a $150 \times 16 \mathrm{~mm}$. tube containing about $10 \mathrm{cc}$. of sterile skimmed milk, which had just previously been heated in an Arnold sterilizer at $100^{\circ} \mathrm{C}$. for 10 or 15 minutes. With a fresh pipette the $10^{-1}$ dilution was thoroughly mixed by blowing, and similar transfers made. Dilutions were carried often as high as $10^{-10}$. In cases with known high spore counts cultures of the lower dilutions were usually omitted.

The milk cultures were placed immediately in a Brown (13) anaerobic jar, anaerobiosis established, and the jar placed in the incubator at $37.5^{\circ} \mathrm{C}$. After 3 days incubation the jar was opened and those tubes were called positive which showed typical stormy fermentation with an odor of butyric acid and disclosed in stained smears Gram positive bacilli morphologically resembling B. Welchii. Occasionally coagulation of the milk occurred with or without a moderate number of gas bubbles. In such instances $1 \mathrm{cc}$. was transferred to a fresh milk tube and incubated as above, on the assumption that, if too few $B$. Welchii were present in the original sample to produce stormy fermentation, a sufficient number would be present in the transfer to bring about a definite result. If only coagulation with or without a few gas bubbles occurred after 3 days incubation in the subculture the tube was considered to be negative. Smears of such tubes invariably showed Gram positive bacilli which usually did not resemble $B$. Welchii morphologically. All of the original tubes showing no change in the milk were regarded as negative.

In calculating the number of spores it was assumed that the tube containing the smallest amount of emulsion necessary to produce stormy fermentation, either in the original or subculture, contained one $B$. Welchii spore. It is conceivable that many more spores might be necessary. Assuming the required number to be $\mathrm{K}$, the number per cubic centimeter in an emulsion causing stormy fermentation as far as the $10^{-3}$ tube would be $1000 \times \mathrm{K}$. However, if we assume $\mathrm{K}=1$, the numerical ratio remains the same for the various emulsions and this simpler expression has been used.

With few exceptions stormy fermentation proceeded in an orderly manner, positive through a certain dilution and negative thereafter. Occasionally the first negative tube was followed by a positive with the remainder negative. In 
B. WELCHII IN PERNICIOUS ANEMIA

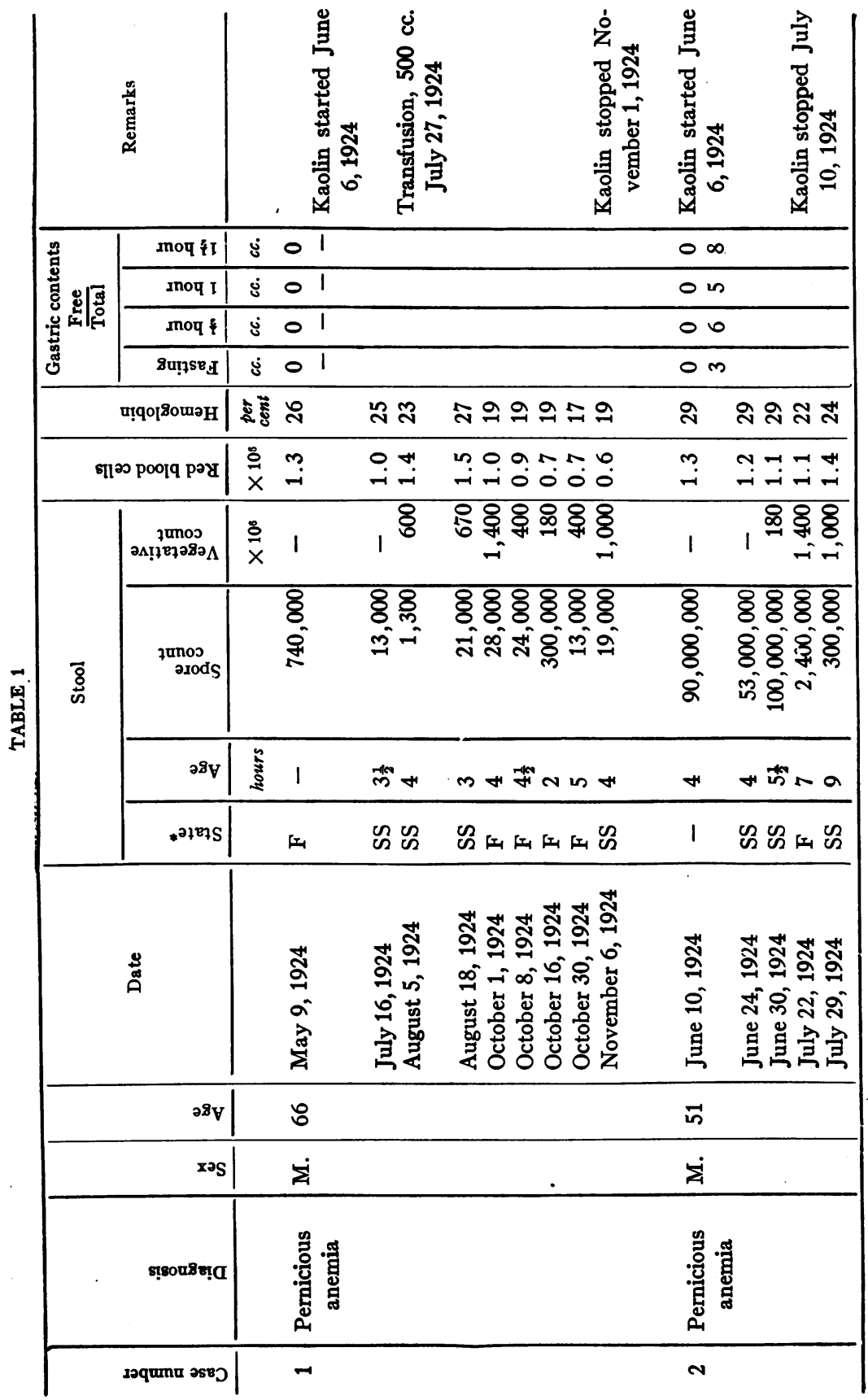




\begin{tabular}{|c|c|c|c|c|c|c|}
\hline \multicolumn{2}{|c|}{ 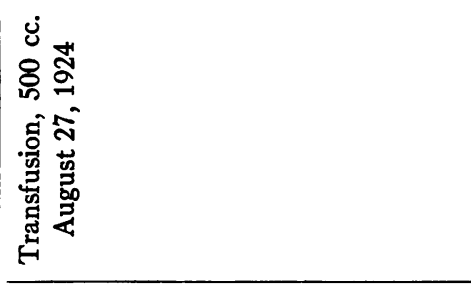 } & 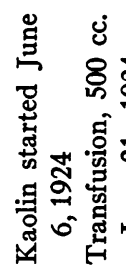 & 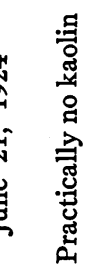 & & & \\
\hline & & 0 in & & \multicolumn{2}{|c|}{0 으 } & $0-1$ \\
\hline & & $0+1$ & & \multicolumn{2}{|c|}{0 으 } & $0-1$ \\
\hline & & \multicolumn{2}{|l|}{$0 \%$} & \multicolumn{2}{|c|}{00} & or \\
\hline & & \multicolumn{2}{|l|}{ ON } & \multicolumn{2}{|l|}{0 in } & OM \\
\hline Iิ & 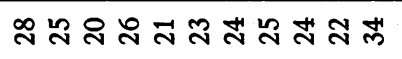 & $\stackrel{\infty}{\sim}$ & $\stackrel{\infty}{\sim} 9$ & 20 & 年午孚 & झ゙ \\
\hline & 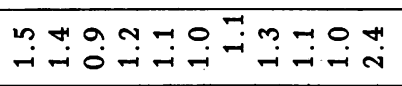 & $\stackrel{\circ}{-} \stackrel{0}{-}$ & $9 \dot{0}$ & & $\vec{i} \stackrel{i}{i}$ & $\stackrel{n}{n}$ \\
\hline & 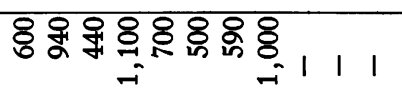 & 18 & 음 & ర్స్ & ఫ్రి ఫ્స్ స్ & $\stackrel{\infty}{\infty}$ \\
\hline & 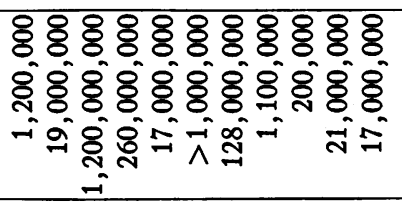 & $\begin{array}{l}8 \\
8 \\
8 \\
0 \\
\text { m }\end{array}$ & $\begin{array}{l}88 \\
88 \\
7\end{array}$ & 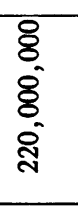 & 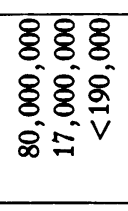 & $\begin{array}{l}\text { \&్ } \\
\text { \& } \\
\text { i }\end{array}$ \\
\hline+ & $n \infty a$ un $+0 \infty n+0 \infty$ & + & $a n$ & $m$ & $+\infty+$ & + \\
\hline 厌 & 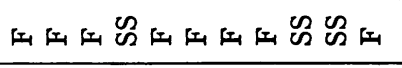 & $\mathscr{2}$ & ๗ิณ & ஜ & 告的的 & $\mathscr{2}$ \\
\hline \multirow[t]{5}{*}{ 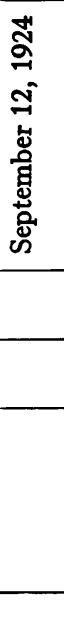 } & 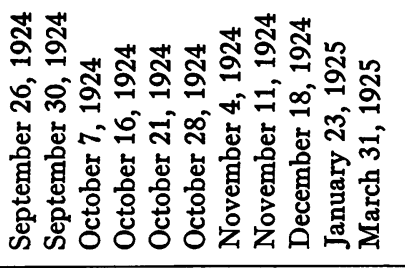 & 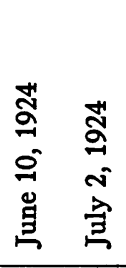 & 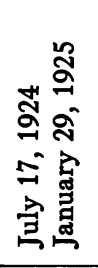 & 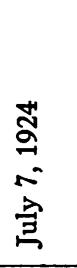 & 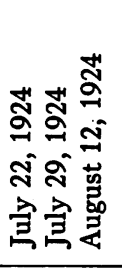 & 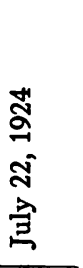 \\
\hline & & in & & \multicolumn{2}{|l|}{ ชิ } & \& \\
\hline & & $\dot{\Sigma}$ & & $\dot{\Sigma}$ & & si \\
\hline & & 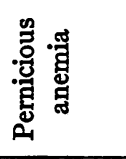 & & 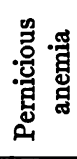 & & 冚 : \\
\hline & & $m$ & & + & & is \\
\hline
\end{tabular}




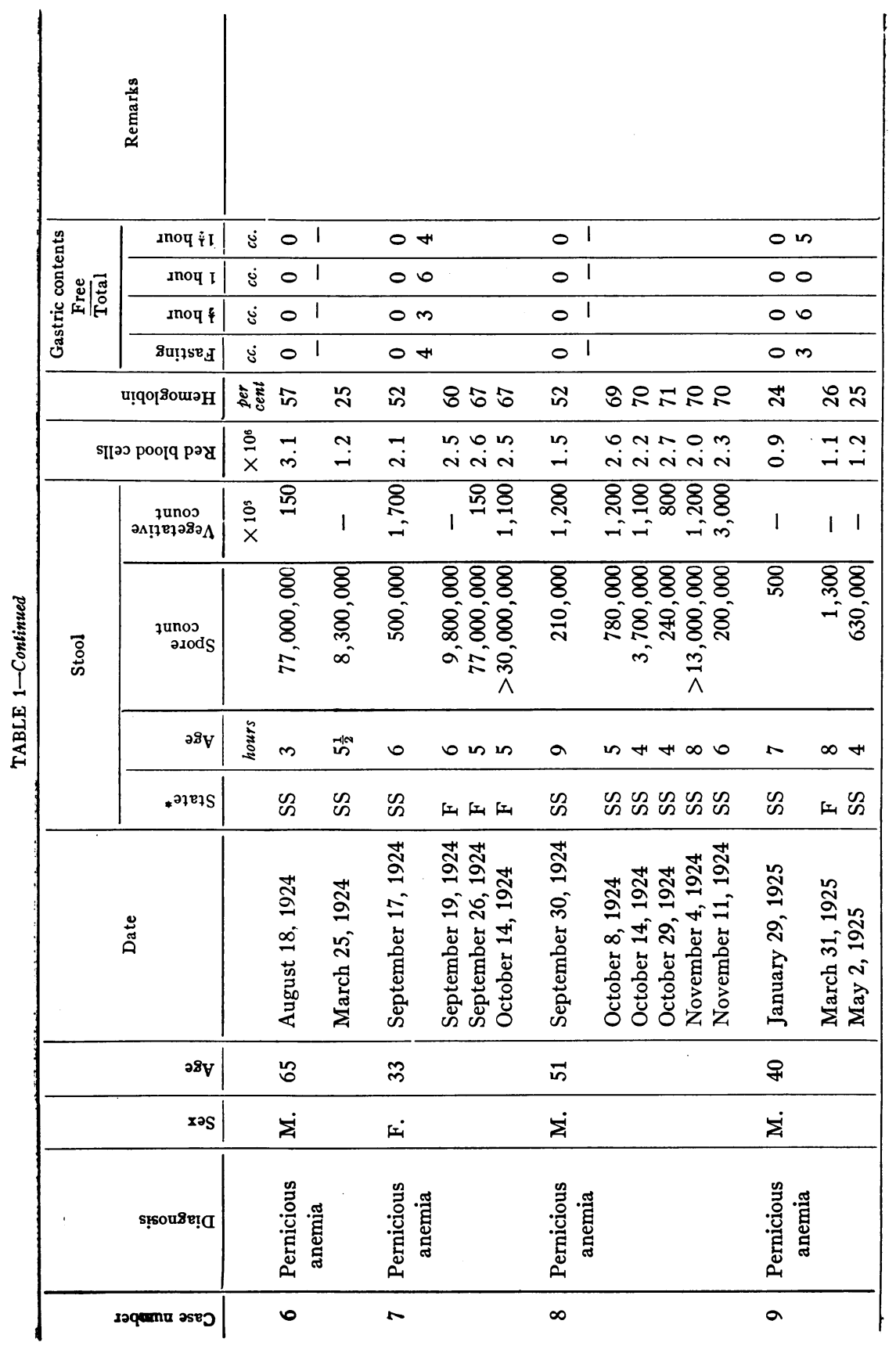




\begin{tabular}{|c|c|c|c|c|c|c|c|c|}
\hline 11 & 01 & & & & & & & \\
\hline $0 \exists$ & 01 & & & & & & & \\
\hline 11 & 01 & & & & & & & \\
\hline $0 a$ & 01 & & & & & & & \\
\hline 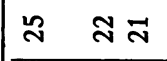 & กิ & $\infty$ & 1 & 1 & 1 & 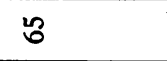 & $\infty$ & 1 \\
\hline $\begin{array}{lll}0 & 0 & - \\
0 & -i & 0\end{array}$ & $\dot{0}$ & 1 & 1 & 1 & 1 & $\stackrel{0}{0}$ & $\stackrel{H}{+}$ & 1 \\
\hline 111 & 1 & 1 & 1 & 1 & 1 & 1 & 1 & 1 \\
\hline 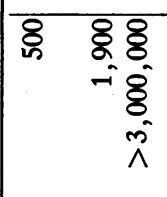 & $\begin{array}{l}8 \\
8 \\
8 \\
\\
i \\
i\end{array}$ & $\sqrt{N}$ & 8 & प्र & $\begin{array}{l}8 \\
8 \\
0\end{array}$ & 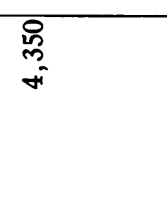 & & 을. \\
\hline in +0 & + & 1 & 1 & 0 & $H$ & 0 & in & in \\
\hline 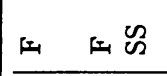 & $\mathscr{2}$ & 1 & 1 & w & ⿷匚 & 5 & 4 & w \\
\hline 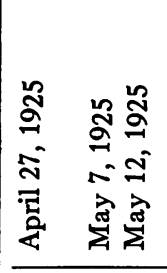 & 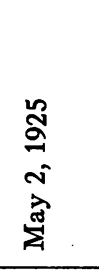 & $\begin{array}{l}\text { J } \\
\vdots \\
0 \\
\Xi \\
\Xi \\
\end{array}$ & 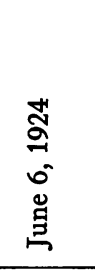 & 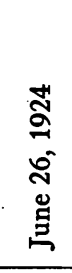 & 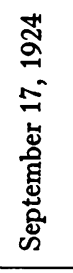 & 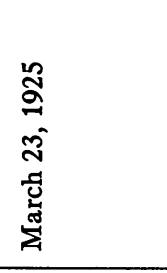 & 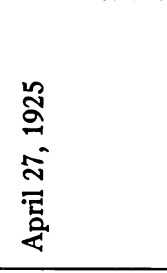 & 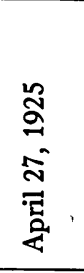 \\
\hline$\stackrel{\infty}{+}$ & $\tilde{m}$ & \& & \& & ส & లే & aิ & สิ & $\stackrel{m}{m}$ \\
\hline Li & $\dot{\Sigma}$ & $\dot{\Sigma}$ & $\dot{\Sigma}$ & is & $\dot{\Sigma}$ & $\dot{\Sigma}$ & is & $\dot{\Sigma}$ \\
\hline 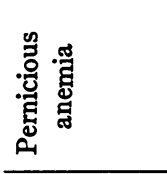 & 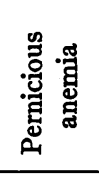 & 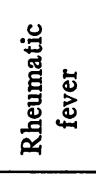 & 苨 & 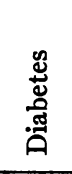 & 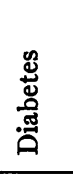 & 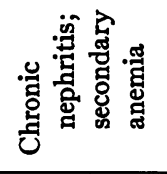 & . 蒫总总 & 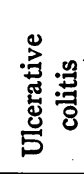 \\
\hline 웅 & $=$ & $\cong$ & $m$ & \pm & 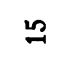 & $\stackrel{2}{\circ}$ & $=$ & $\stackrel{\infty}{\sim}$ \\
\hline
\end{tabular}




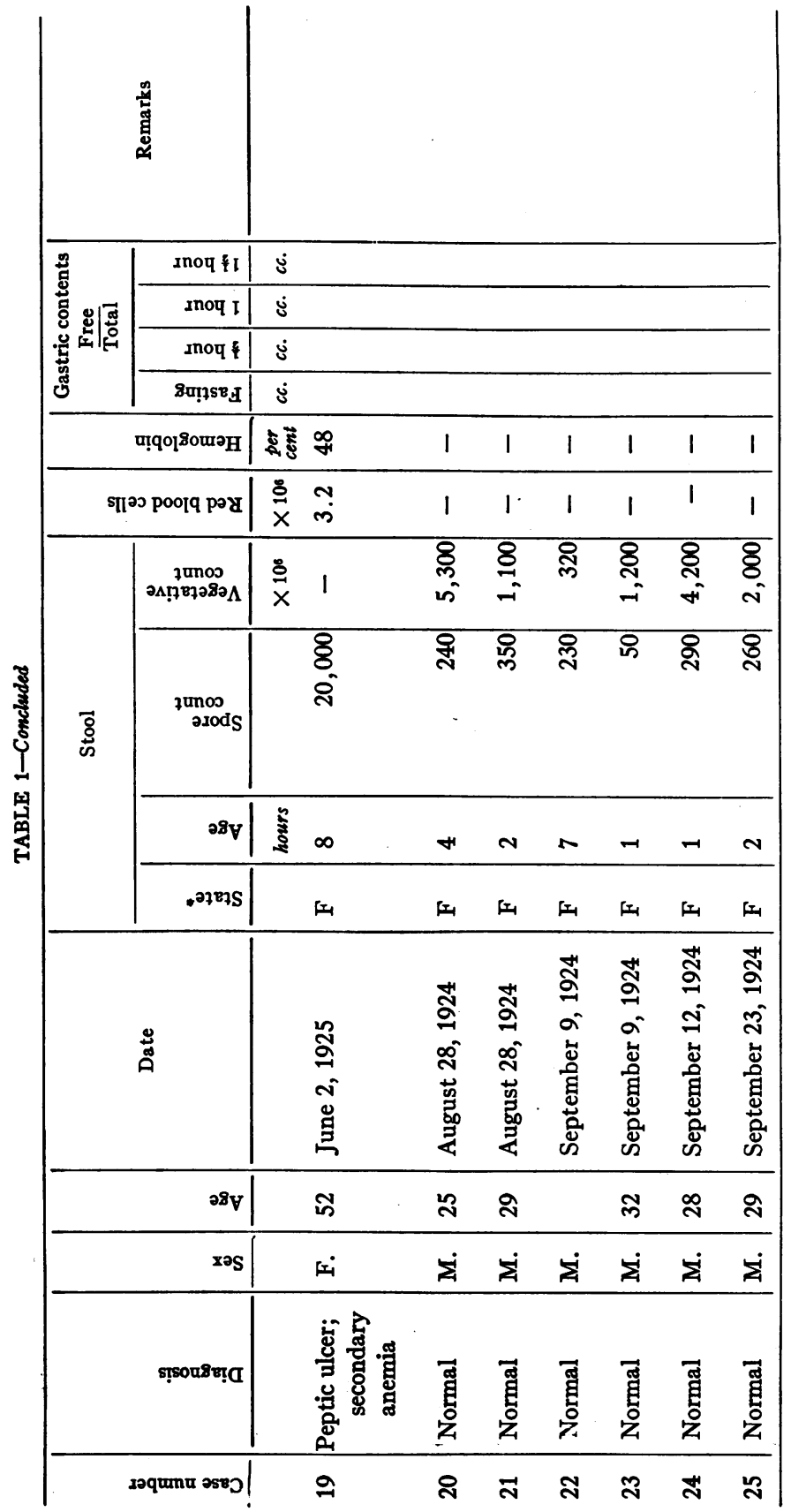


such an instance the first negative tube was regarded as the last positive, on the assumption that the one spore, or " $K$ " spores, necessary to cause stormy fermentation had by chance been carried over into the next dilution.

To compensate for the varying water content of the stool, the results can be expressed, as suggested by Simonds, as "spores per gram dried stool." The calculation is simple, for example:

$10^{-0}=$ last positive culture

2.5 grams $=$ weight dried stool in $100 \mathrm{cc}$. emulsion

$\frac{100}{2.5} \times 10^{6}=40,000,000=$ spores per gram dried stool

In table 1 are tabulated the spore counts in stools from 11 cases of pernicious anemia, 8 cases of miscellaneous disease, and 6 normals. Fifty-four individual counts were made on the 11 cases of pernicious anemia. The averages for all counts in each group are 46,000,000, 3400 and 240 per gram of dried stool respectively. These figures confirm the findings of previous workers, namely, that $B$. Welchii spores are markedly increased in stools from cases of pernicious anemia.

Simonds (2) found that $B$. Welchii spores in stools from normal individuals were greatly increased during diarrhea. For this reason objections might be raised as regards the reliability of the results because of the varying water content of the stools. As previously stated, all diarrhea stools and enema stools were discarded. It seemed to make no difference whether the stools were semisolid or formed. For example, in case 2, the samples described as formed gave counts ranging from $1,100,000$ to $1,200,000,000$ and those described as semisolid gave counts varying from 200,000 to $260,000,000$.

As the period of time from passage of the stool to dilution varies from 1 to 9 hours it is conceivable that this might have considerable influence on the results. One might expect an increase in the number of spores as the interval was prolonged. As a matter of fact, in 6 of the 9 cases of pernicious anemia in which two or more specimens were examined the average of counts with long intervals was somewhat lower than that of those with short intervals.

If the disease, pernicious anemia, is caused by chronic intestinal infection with $B$. Welchii, and if the spore counts are indicative of the numbers of vegetative or active forms of the bacillus, one would expect to find high counts during relapses and low counts during 
remissions, particularly as Kahn and Torrey (11) have shown experimentally that the blood changes in monkeys following intravenous injection of $B$. Welchii toxin are rapid. In cases 4 and 10 such a relation seems to exist. In the former there is a marked decrease coincident with clinical improvement, whereas in the latter the reverse is true. In cases 6 and 7, however, the highest counts are found during periods of relative or absolute remission, and the lowest counts during periods of relative or absolute relapse. These findings seem to indicate that there is no definite relation between the spore counts and the clinical condition of the patient.

In the first three cases an attempt was made to produce clinical improvement by the administration of kaolin, on the assumption that pernicious anemia might be due to chronic intestinal infection with B. Welchii. Walker (14) states that kaolin, as a spray, has been used successfully in Germany in the treatment of faucial diphtheria, and, by ingestion, has been employed for ptomaine poisoning and dysentery; Braafladt (15) showed that kaolin is capable of rendering inocuous appreciable amounts of dysentery, botulinus and diphtheria toxins in vitro; and Eyre (16) observed that large amounts of diphtheria and dysentery toxins are removed by filtering through kaolin filters. Braafladt also found that $B$. Welchii spores could be eliminated from normal stools by feeding kaolin, although the importance of the observation is somewhat diminished by the fact that the maximum amount cultured was only equivalent to approximately 0.0001 gram dried stool. Kaolin was given daily, just before retiring, in 30 gram amounts in orange juice. In this series treated with kaolin, cases 1 and 3 showed a decided reduction in the number of spores. In case 2 treatment had little if any effect. The typical clinical course of the disease was apparently not influenced in the slightest by the spore reduction in cases 1 and 3 .

In the routine cultures of stools from diseases other than pernicious anemia several spore counts were made on 2 cases of relatively mild secondary anemia. All of the samples gave high spore counts, and an attempt was made to account for the apparent discrepancy. Both cases were known to have gastric achylia. The achylia and the anemia seemed to be the only features in common with cases of per- 
nicious anemia. In order to determine the ruling factor, a number of cases of secondary anemia were selected for study, some with and others without gastric achylia. The results, as tabulated in table 2, were startling. The average of all spore counts on the stools from the cases with achylia, cases 26 through 30 , was $51,000,000$, whereas in the cases without achylia, cases 31 through 36 , the average was 1200.

Vegetative $B$. Welchii counts. If $B$. Welchii is to be considered as an etiological factor in pernicious anemia, some effort should be made to estimate the number of active or vegetative forms of this organism in the gastro-intestinal tract. Obviously this would be most difficult to accomplish by cultural methods, because of the presence of overwhelming numbers of other bacteria. The morphology of $B$. Welchii is fairly characteristic when stained by Gram's method, but it is, of course, impossible to distinguish between them and certain others of the less common sporulating anaerobic bacilli. In view of the fact, however, that Kahn (8) and Moench, Kahn and Torrey (9) found that $B$. Welchii were the only sporulating anaerobes which could be recovered consistently from the stools of pernicious anemia patients, it was felt that a simple counting of the forms morphologically resembling $B$. Welchii might furnish valuable information.

Method. With a wax pencil a line was drawn across a clean glass slide $20 \mathrm{~mm}$. from one end. On the area $(20 \times 25 \mathrm{~mm}$.) marked off were placed 9 loopfuls of distilled water. A loopful of the shaken stool suspension, after filtering through gauze, was mixed with the 9 loopfuls of water and spread out as evenly as possible over the area. The same loop ( $3 \mathrm{~mm}$. in diameter) was used for all of the transfers: The smear was allowed to dry in the air. It was then fixed by heat and stained by the Gram method. As B. Welchii is extremely Gram "fast," decolorization with alcohol was carried on about twice as long as usual. No counterstain was used.

For microscopic examination a mechanical stage was used and 12 fields, each $5 \mathrm{~mm}$. apart, were examined. All fat, short to medium length bacilli occurring singly, or rarely in pairs, were included in the count. Extremely long and relatively slender forms were not included. The total number in all fields divided by 12 gave the average per field. With a tube length of $16.0 \mathrm{~cm}$. the diameter of the oil immersion field was $0.15 \mathrm{~mm}$. The volume contained in 1 loopful was determined by weighing the loop with and without distilled water, and found to be 0.0012 cc. Assuming, for example, that the total count of the 12 fields was 5, 


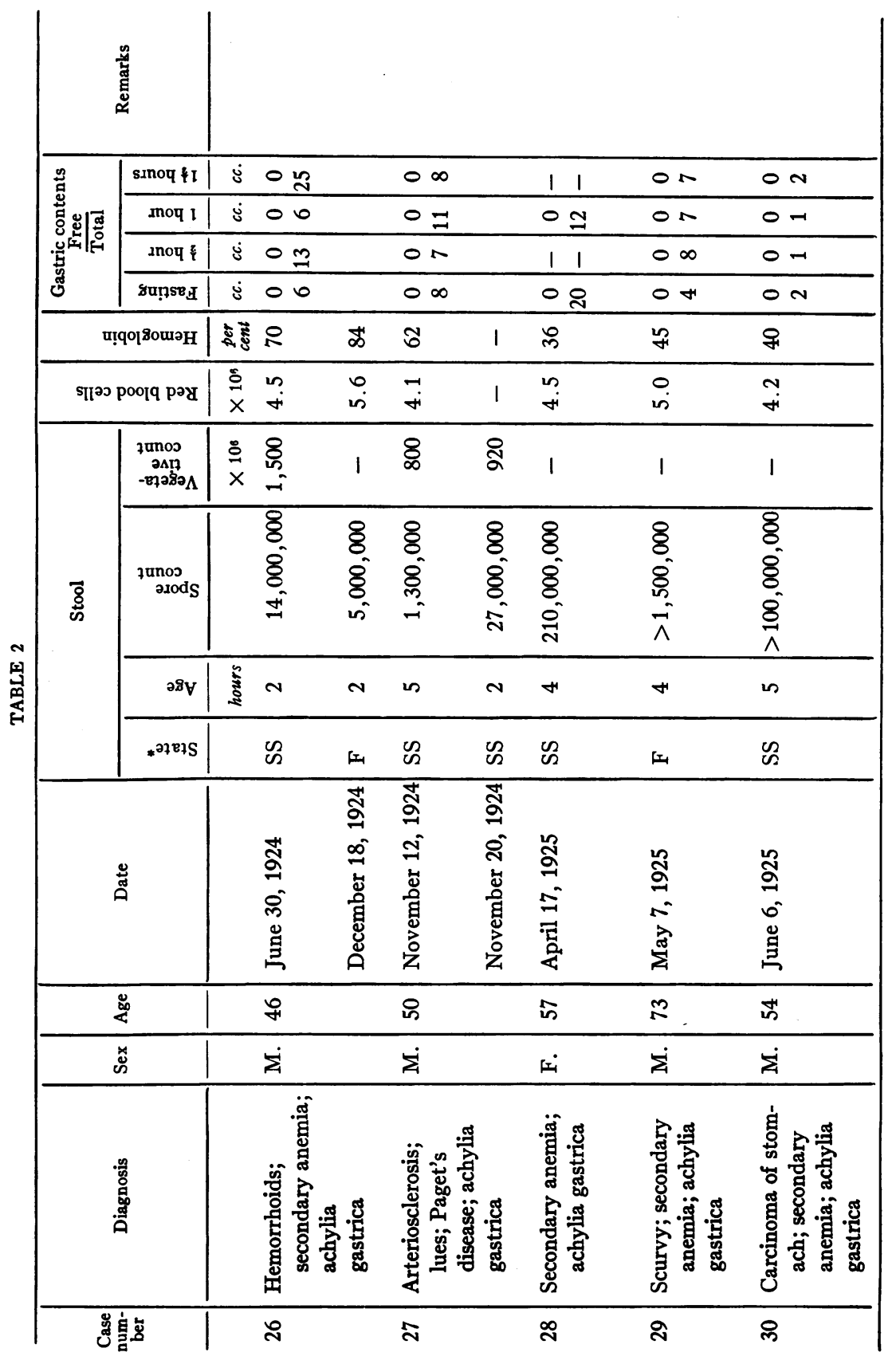




\begin{tabular}{|c|c|c|c|c|c|}
\hline 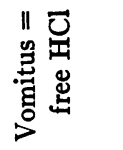 & & & & & \\
\hline 11 & 11 & - & 11 & స & 으으 \\
\hline 11 & 11 & $n \hat{\sim}$ & 11 & 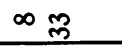 & $\pm \infty$ \\
\hline 11 & +2 & $\circ \stackrel{2}{2}$ & 11 & 요 & $\infty \simeq$ \\
\hline 11 & 00 & ㅇㅇㅡ & 으음 & $+m$ & $0 \mathrm{~m}$ \\
\hline స్లు & ా & ד্ర & $\stackrel{\sim}{\sim}$ & $\hat{0}$ & นก \\
\hline$\stackrel{+}{m}$ & $\stackrel{0}{\dot{m}}$ & $\stackrel{+}{m}$ & $\stackrel{\circ}{\circ}$ & $\overrightarrow{+}$ & $m$ \\
\hline 1 & 1 & 1 & 1 & 1 & 1 \\
\hline $\mathscr{F}$ & ర్లి & $\begin{array}{l}8 \\
\\
-1\end{array}$ & $\begin{array}{l}8 \\
\\
+\end{array}$ & ষ্ల & : \\
\hline in & $H$ & $H$ & in & 0 & $\infty$ \\
\hline $\mathscr{N}$ & $\mathscr{2}$ & $\mathscr{2}$ & $\tilde{2}$ & $\mathscr{N}$ & $\mathscr{2}$ \\
\hline 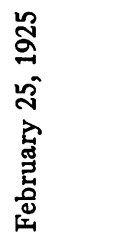 & 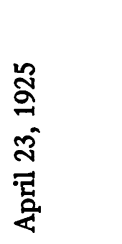 & 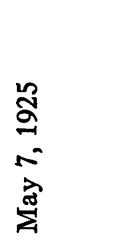 & 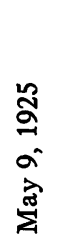 & 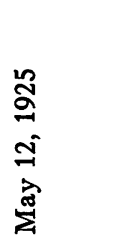 & 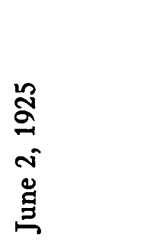 \\
\hline $\mathfrak{N}$ & 8 & 오 & 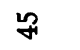 & $\stackrel{\infty}{\not}$ & $\mathscr{F}$ \\
\hline मxi & $\dot{\Sigma}$ & $\dot{\Sigma}$ & $\stackrel{\Sigma}{\Sigma}$ & $\dot{\Sigma}$ & $\dot{\Sigma}$ \\
\hline 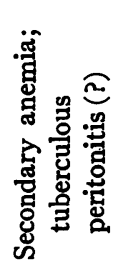 & 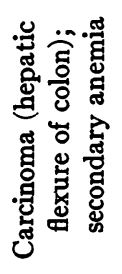 & 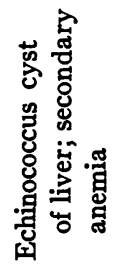 & 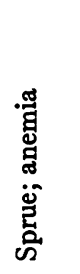 & 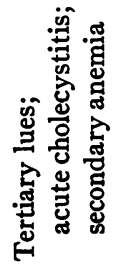 & 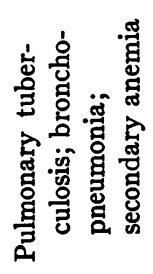 \\
\hline$\vec{m}$ & స్లా & $\ddot{m}$ & 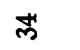 & ஜ & 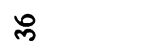 \\
\hline
\end{tabular}


the average count per field would be $\frac{5}{12}$ and the count of a stool which contained in suspension 5.0 grams per $100 \mathrm{cc}$. would be calculated as follows:

$$
\begin{aligned}
& \text { Area of field }=\left(\frac{0.15}{2}\right)^{2} \pi=0.0176 \text { sq. mm. } \\
& \text { Area of smear }=25 \times 20=500 \text { sq. mm. } \\
& \text { Fields per smear } \frac{500}{0.0176}=28,000 \\
& \text { Count per loop }=\frac{5}{12} \times 28,000=12,000 \\
& \text { Count per cc. }=12,000 \times \frac{1}{0.0012}=10,000,000 \\
& \text { Count per gram dried stool }=\left(10 \times 10^{6}\right) \times \frac{100}{5}=200 \times 10^{8}
\end{aligned}
$$

The results of the vegetative counts are given in tables 1 and 2 . The average of 36 stools from cases of pernicious anemia was $1000 \times$ $10^{6}$ and of 3 stools from cases of gastric achylia $1100 \times 10^{6}$. Counts of six normal stools averaged $2400 \times 10^{6}$. In the 39 pernicious anemia and achylia specimens there were only 3 giving counts higher than $1700 \times 10^{6}$, whereas in the normals 3 out of 6 were higher than this figure. Undoubtedly many of the organisms counted were dead. This applied, however, to both sets of figures, and furthermore, even though the bacilli were dead, the count would seem to be indicative of the actual number of live organisms high up in the actively absorbing portions of the intestinal tract. Although it must be acknowledged that the method is very crude, the figures are sufficiently accurate to show that normal stools contain at least as many, probably more, vegetative forms of the sporulating anaerobic bacilli as stools from cases of pernicious anemia and gastric achylia.

\section{DISCUSSION}

It has always been possible to demonstrate the presence of $B$. Welchii spores in stool specimens regardless of their source in the amounts used for culture. Confirming the work of several other investigators it has been shown that in pernicious anemia these spores are usually increased to a marked degree.

On the basis of the last observation, together with the blood changes 
brought about either by the intravenous injection of $B$. Welchii toxin (Kahn and Torrey (11)), or by chronic $B$. Welchii infection (Cornell (10)), it has been suggested that chronic intestinal infection with $B$. Welchii may very possibly be the cause of pernicious anemia. Is it fair to assume that because of an increased spore count there is an accompanying increase in vegetative or active forms? All other things being equal such might be the case. The ratio of spores to vegetative forms in stools from cases of pernicious anemia is $1: 20$, whereas in normal stools, assuming that 50 per cent of the vegetative forms are $B$. Welchii, the ratio is $1: 5,000,000$. This extraordinary difference would seem to indicate that in pernicious anemia some change has taken place in the gastro-intestinal tract which either favors spore formation, inhibits growth of the organism or combines these two possibilities. In view of the fact that in both instances the vegetative counts are approximately the same, it seems more logical to assume that the marked increase in spores is due to some change in the gastro-intestinal tract favorable to spore formation.

$B$. Welchii, unlike the majority of the other anaerobic bacilli belonging to the same group, such as Vibrion septique, B. edematiens $B$. sporogenes and $B$. histolyticus; does not readily produce spores. For their formation in culture media a slightly alkaline reaction is essential. In media containing fermentable sugars, and hence variaable amounts of acid, spores are rarely formed. Simonds (2) found that $B$. Welchii spores were not formed in sterilized adjusted fecal suspensions inoculated with either pure $B$. Welchii cultures or mixtures containing $B$. Welchii and $B$. coli or $B$. subtilis, provided the acidity of such suspensions was equivalent to 1.0 per cent normal hydrochloric or acetic acid (phenolphthalein used as indicator). Furthermore, in unsterilized fecal suspensions known to contain $B$. Welchii, and to which were added 1.0 per cent of various fermentable sugars (lactose, maltose and saccharose), $B$. Welchii spores were not found provided the final acidity was greater than 4.0 per cent. Expressed in terms of hydrogen ion concentration it will be found that a 10 per cent fecal suspension adjusted to 1.0 and 4.0 per cent acid (normal $\mathrm{HCl}$ ), using phenolphthalein as an indicator, will have a $\mathrm{pH}$ of approximately 7.5 and 5.0 respectively.

Cannon (17), in his studies on normal persons and rats, observed 
that a diet relatively rich in carbohydrates results in an aciduric fecal flora with an accompanying decrease or absence of $B$. Welchii spores. Cannon and McNease (18) studied the reaction and flora of the cecum and colon of white rats on meat and on meat and lactose diets. On the former diet the intestinal contents were foul in odor, had a $\mathrm{pH}$ of 7.0-7.1 and contained a flora predominantly proteolytic, forming gas in deep Viellon tubes of whey agar. When lactose was added to the diet the offensive odor disappeared, the acidity of the contents increased (cecum $=\mathrm{pH} 4.5$ and colon $=\mathrm{pH}$ 5.7), the flora became predominantly aciduric and the Viellon tubes usually showed no gas production. A corresponding increase in acidity of the cecal and colonic contents accompanied by a shift from proteolytic to aciduric flora was observed in white rats by Hudson and Parr (19), when a diet rich in carbohydrates was substituted for one containing meat. By feeding kaolin Braafladt (15) brought about a similar shift from the normal proteolytic flora of man and dogs to a flora of the aciduric type accompanied by a marked quantitative decrease in $B$. Welchii spores. Hines (20), in studying the intestinal flora in diarrhea noted a marked increase of $B$. Welchii spores in the diarrheas characterized by a proteolytic flora, and either an absence ( 2 cases) or a normal number (1 case) of spores in those with an aciduric flora.

The various observations mentioned above would seem to indicate that the reaction of the gastro-intestinal contents is an important factor in $B$. Welchii spore formation. In conditions accompanied by an aciduric flora and by an increase in acidity of the intestinal contents there is a marked decrease in the number of $B$. Welchii spores. Moench, Kahn and Torrey (9), on the basis of their study of the intestinal flora in cases of pernicious anemia, have concluded that the flora is non-proteolytic in type. Such a conclusion seems hardly justifiable, for in the 16 cases, in which the colonies on acid whey agar were identified, the $B$. coli- $B$. acidophilus ratio appears to average 94 to 6. Furthermore, the usual characteristics of stools from cases of pernicious anemia, such as, foul odor and the presence of large amounts of undigested vegetable material, suggest a flora of the proteolytic type. This inhibitory effect of acidity on sporulation and the marked increase of $B$. Welchii spores in stool specimens from cases of gastric achylia, with or without pernicious anemia, suggest that the increase 
may be secondary to the achylia, i.e., the result of changes in reaction favorable to sporulation brought about in some portion of the gastro-intestinal tract by the absence of normal gastric juice.

Very little is known concerning the reaction of the content of the normal small intestine. Some of the standard text books state that it is slightly alkaline and others that it is acid. The average of 9 electrometric determinations in 3 normal subjects by Long and Fenger (21), which were made within $6 \frac{1}{2}$ hours after normal meals and when the tip of the Rehfuss tube was shown by $x$-ray to be beyond the duodenal-jejunal junction, was $\mathrm{pH}$ 5.83. Apparently no precautions were taken, however, against loss of $\mathrm{CO}_{2}$ in transportation of the specimens from the clinic to the laboratory, and measurements were made in a type of electrode (Hasselbalch) which would further tend to dilute the $\mathrm{CO}_{2}$ content. Above $\mathrm{pH} 5.5$ such a loss would undoubtedly decrease the acidity. The most accurate observations are those of McClendon, Bissell, Lowe and Meyer (22). Two normal subjects (age about 25) were studied for a period of 4 days. The Rehfuss tubes swallowed were 7 feet in length and eventually (on the fourth day) reached about the midportion of the jejunum. Twelve samples were removed from $1 \frac{1}{2}$ to 3 hours after ordinary meals. The average acidity was $\mathrm{pH} 5.2$ with a maximum of $\mathrm{pH} 4.1$ and a minimum of $\mathrm{pH}$ 6.5. Measurements made on the fourth and fifth days, i.e., after the tubes had nearly reached the maximum depth, averaged somewhat higher ( $\mathrm{pH}$ 5.4) than those made on the first two days ( $\mathrm{pH} 4.8$ ). All measurements were made electrometrically and loss of $\mathrm{CO}_{2}$ was prevented. From the above data it seems logical to assume that normally the contents of the small intestine, at least as far as the midportion of the jejunum, are decidedly on the acid side of neutrality-a reaction unfavorable to the formation of $B$. Welchii spores.

The chief contribution to the acidity of the upper intestinal contents must be the gastric juice, which normally is usually considered equivalent to $1500 \mathrm{cc}$. of $\mathrm{N} / 10 \mathrm{HCl}$ per day. The pancreatic juice is strongly alkaline, the intestinal juice somewhat less alkaline, and bile slightly alkaline. In conditions of achylia it is difficult to conceive of the reaction of the upper intestinal contents as being anything but alkaline. In the normal gastro-intestinal tract it seems probable that the gastric juice and the acid by-products of digestion 
are sufficient to keep the reaction of the intestinal contents on the acid side of neutrality as far as the lower ileum, and possibly the cecum. The reaction is such that spore formation can not occur to any marked degree until the colon is reached. In conditions of achylia, however, spores may be formed not only in the large intestine, but also in the small intestine.

The importance of the normal secretion of gastric juice in determining the flora of the small intestine has been recently emphasized by Bogendörfer (23) and by Arnold and Brody (24). The former was able to recover $B$. coli and $B$. Welchii from the contents of the upper small intestine (tube length 2.0-2.5 meters) in cases of anacidity and gastric achylia including 2 cases of pernicious anemia, whereas those organisms were never found in cases with normal gastric secretion. The latter have reported a series of experiments on dogs in which the bacterial flora of the duodenum and upper jejunum has been shifted to resemble that of the ileum and colon by changing the normal reaction $(\mathrm{pH} 5.0-6.0)$ to neutral or slightly alkaline $(\mathrm{pH} 7.0-8.0)$. Van der Reis (6) (25) has demonstrated that a similar shift of flora nccurs in cases of pernicious anemia. In addition to $B$. coli in the upper portions of the small intestine, he was able to recover sporulating anaerobic bacilli from the middle and lower portions-results not obtainable in cases without achylia.

It seems probable that $B$. Welchii is not a normal inhabitant of the upper small intestine. In the presence of achylia, however, this organism, together with others, notably $B$. coli, characteristic of the flora of the colon, work their way upwards and may be recovered even as high as the duodenum. It is not surprising that a marked increase in $B$. Welchii spore formation should occur. One would expect an increase in vegetative forms, but curiously such an increase can not be demonstrated, at least by the method of stained smear preparations of the feces.

Several other facts and observations tend to oppose the hypothesis that $B$. Welchii is the etiological factor in pernicious anemia. In the first place, the severe diarrheas accompanied by, possibly due to, a marked increase of $B$.Welchi in the intestinal contents do not result in any noteworthy anemia. Secondly, the experimental anemias brought about by Kahn and Torrey (11) are very acute in character, 
identical with those brought about by the intravenous injections of any powerfully hemolytic agent, and, furthermore, there is marked reaction by the animal in the production of antihemolysin. Thirdly, Tenbroeck and Bauer (26) have demonstrated appreciable amounts of tetanus antitoxin in the serums from human beings harboring spores of $B$. tetanus in their gastro-intestinal tracts and from guinea pigs which have been fed large amounts of tetanus spores, and they remark that in the latter, although the tetanus bacillus is known to produce powerful hemolysins, no ill effects were noted. If pernicious anemia were due to continued absorption of $B$. Welchii toxin from the gastro-intestinal tract one would expect to find the tissue cells active in antitoxin production. Failure in certain individuals to produce antitoxin, either because of inherent inability or possibly toxin hypersusceptibility, might result in the development of severe anemias. In such an instance one would expect to find a relatively low concentration of $B$. Welchii antihemolysins in the serum, and probably a marked reaction following intradermal injection of B. Welchii toxin. Preliminary experiments indicate that the toxin neutralizing properties of the serums and the skin reactions of individuals suffering from pernicious anemia are essentially identical with those of normal individuals. These investigations have not been carried out in sufficient detail to warrant inclusion in the present paper.

The abnormal flora of the small intestine, secondary to the gastric achylia, may very possibly result in changes in the gastro-intestinal tract which eventually lead to the disease, pernicious anemia. Weinberg (27) believes that true achylia gastrica (not achylia secondary to chronic gastritis) is an hereditary condition, and that the individuals born with achylia gastrica are the ones in whom pernicious anemia may eventually develop. Many other investigators, however, are opposed to the idea, and it does seem quite unusual that the development of pernicious anemia should be deferred so many years.

\section{CONCLUSIONS}

1. In stools from cases of pernicious anemia there is a great increase in the number of $B$. Welchii spores as compared with normal stools and stools from the majority of cases of miscellaneous disease. 
2. This same increase in $B$. Welchii spores is also present in stools from cases of gastric achylia without pernicious anemia.

3. Counts of vegetative forms would seem to indicate that in any of the above conditions the number of active or vegetative forms of $B$. Welchii present in the stools are practically the same.

4. On the basis of the above observations and the tendency of $B$. Welchii to form spores in alkaline media, it seems logical to assume that the spore increase in pernicious anemia is secondary to the gastric achylia rather than indicative that pernicious anemia is caused by chronic intestinal infection with $B$. Welchii.

I wish to express my indebtedness to Dr. G. O. Broun and Dr. P. $\mathrm{H}$. Long for collection and preliminary preparation of the specimens and to Miss Carolyn Ladd for technical assistance.

\section{BIBLIOGRAPHY}

1. Herter, C. A., J. Biol. Chem., 1906-1907, ii, 1. On Bacterial Processes in the Intestinal Tract in Some Cases of Advanced Anemia, with Especial Reference to Infection with B. aerogenes capsulatus (B. Welchii).

2. Simonds, J. P., Monographs of the Rockefeller Institute for Medical Research, No. 5, 1915. Studies in Bacillus Welchii, with Special Reference to Classification and to Its Relation to Diarrhea.

3. Klotz, O., and Holman, W. L., J. Infect. Dis., 1911, ix, 251. Infection by the Gas Bacillus in Coal Mines.

4. Schumm, O., Abstract Berl. klin. Wchnschr., 1913, i, 517. Aerztlicher Verein zur Hamburg.

5. Hunter, W., Pernicious Anaemia: Its Pathology, Septic Origin, Symptoms, Diagnosis, and Treatment, London, 1901; and Severest Anaemias; Their Infective Nature, Diagnosis and Treatment, London, 1909.

6. Van der Reis, V., Zeit. f. ges. exp. Med., 1923, xxxv, 296. Utber die Bakterienflora des Darms. III. Die Flora des Dünndarms bei pathologische Zuständen.

7. Seyderhelm, R., Die Pathogenese der Perniziösen Anämie, Berlin, 1922.

8. Kahn, M. C., J. Infect. Dis., 1924, xxxv, 423. Anaerobic Spore-bearing Bacteria of the Human Intestine in Health and in Certain Diseases.

9. Moench, L. M., Kahn, M. C., and Torrey, J. C., J. Infect. Dis., 1925, xxxvii, 161. Analysis of the Fecal Flora in Thirty-three Cases of Pernicious Anemia with Particular Reference to $B$. Welchii.

10. Cornell, B. S., (a) J. Infect. Dis., 1925, xxxvi, 425. A Chronic Infection with $B$. Welchii. (b) J. Infect. Dis., 1925, xxxvi, 508. Blood Changes in $B$. Welchii Infection. 
11. Kahn, M. C., and Torrey, J. C., Proc. Soc. Exper. Biol. \& Med., 1925, xxiii, 8. A Pernicious Anemia-like Blood Condition Produced in Monkeys with B. Welchii Toxin.

12. Patterson, M. B., and Kast, L., Proc. Soc. Exper. Biol. \& Med., 1925, xxiii, 171. Bacillus Welchii as an Agent in Experimental Anemia.

13. Brown, J. H., J. Exper. Med., 1922, xxxv, 467. Modification of an Improved Anaerobic Jar.

14. Walker, R. R., Lancet, 1921, ii, 273. The Action and Uses of Kaolin in the Treatment of Asiatic Cholera.

15. Braafladt, L. H., J. Infect. Dis., 1923, xxxiii, 434. The Effect of Kaolin on the Intestinal Flora in Normal and Pathologic Conditions.

16. Eyre, J. W. H., Lancet, 1925, i, 1124. Colloidal Kaolin. II. The Absorption of Toxin by Kaolin.

17. Cannon, P. R., J. Infect. Dis., 1921, xxix, 369. The Effects of Diet on the Intestinal Flora.

18. Cannon, P. R., and McNease, B. W., J. Infect. Dis., 1923, xxxii, 175. Factors Controlling Intestinal Bacteria - the Influence of Hydrogen-ion Concentration on Bacterial Types.

19. Hudson, N. P., and Parr, L. W., J. Infect. Dis., 1924, xxxiv, 621. Relation of Reaction of Intestinal Contents to Diet and Flora.

20. Hines, L. E., J. Infect. Dis., 1923, xxxii, 280. Intestinal Flora in Diarrhea.

21. Long, J. H., and Fenger, F., J. Am. Chem. Soc., 1917, xxxix, 1278. On the Normal Reaction of the Intestinal Tract.

22. McClendon, J. F., Bissell, F. S., Lowe, E. R., and Meyer, P. F., J. Am. Med. Ass., 1920, lxxv, 1638. Hydrogen-ion Concentration of the Contents of the Small Intestine.

23. Bogendörfer, L., Deutsches Arch. f. klin. Med., 1922, cxl, 257. Uber die Flora des menschlichen Dündarmes.

24. Arnold, L., and Brody, L., J. Infect. Dis., 1926, xxxviii, 249. Bacterial Flora and Hydrogen-ion Concentration of Duodenum.

25. Van der Reis, V., Klin. Wchnschr., 1922, i, 950. Die Bakterienflora des Dünndarms und des Coecums bei Erwachsenen unter normalen und pathologischen Verhältnissen.

26. Tenbroeck, C., and Bauer, J. H., (a) J. Exper. Med., 1923, xxxvii, 479. Studies on the Relation of Tetanus Bacilli in the Digestive Tract to Tetanus Antitoxin in the Blood. (b) Proc. Soc. Exper. Biol. \& Med., 19231924, xxi, 267. Tetanus Carriers in Experimental Animals. (c) J. Exper. Med., 1926, xliii, 361. The Immunity Produced by the Growth of Tetanus Bacilli in the Digestive Tract.

27. Weinberg, F., Deutsches Arch. f. klin. Med., 1918, cxxvi, 447. Achylia gastrica und perniziöse Anämie. 